\title{
The Usefulness Metrics of the Most Popular eReader Used by Higher Education Students
}

\author{
Dwi Puspita Sari, Elicia Lanham, and Lei Pan \\ School of Information Technology \\ Deakin University, Burwood, Victoria, Australia
}

\author{
dpsari.research@gmail.com; elicia.lanham@deakin.edu.au; \\ I.pan@deakin.edu.au
}

\begin{abstract}
In the digital technology era, mobile devices have an important rule to deploy a copy of data and information through the network. An electronic reader (eReader) allows readers to read written materials in an electronic manner that is available in many models. The objective of this study is to evaluate the usage of eReader by higher education students. We firstly identified the most frequently used eReader by surveying higher education students. The survey results showed that Apple iPad, Amazon Kindle, and Samsung Tablet are the most popular eReader devices used by higher education students. We presented these results, and then we analyzed the surveyed results in detail in order to develop an evaluation metric of the eReader in a mobile platform that clearly allows the selection of the most suitable eReader for higher education students. The main contribution of this paper is the development of a set of criteria that can be used by students in the selection of an eReader that matches their specific needs and requirements.
\end{abstract}

Keywords: eReader, evaluation, usefulness metric

\section{Introduction}

Living in a digital era encourages ordinary users to access data and information, such as books, newspapers, songs, and films as digital files, where it can be easily copied and deployed using networks (Sena, 2011). Furthermore, digital natives argue that accessing and sharing the information in electronic text/content using dedicated mobile devices is more efficient than the printed form (Stephens, 2012). Digital natives are those who are defined as people who have grown up surrounded by dedicated devices including computers, videos, games, digital music players, and mobile phones (Colorado, 2012). Therefore it is not surprising that these digital natives would take a strong opinion in regards to the adoption of technology over printed resources.

Material published as part of this publication, either on-line or in print, is copyrighted by the Informing Science Institute. Permission to make digital or paper copy of part or all of these works for personal or classroom use is granted without fee provided that the copies are not made or distributed for profit or commercial advantage AND that copies 1) bear this notice in full and 2) give the full citation on the first page. It is permissible to abstract these works so long as credit is given. To copy in all other cases or to republish or to post on a server or to redistribute to lists requires specific permission and payment of a fee. Contact Publisher@,InformingScience.org to request redistribution permission.
According to Nielsen (2014),

Australians have shifted to mobile devices in the recent years. Specifically speaking, $65 \%$ of Australians own smartphone devices, and $47 \%$ of Australians own tablet devices. In fact, many Australians use eReaders for personal use but little research has been conducted in Australia to evaluate the usefulness of eReaders. The increasing percentage of Australians using on 
eReader devices has encouraged researchers to identify the most popular eReaders used by higher education students; in particular, this study will focus on developing set of positive and negative metrics from the most popular eReaders that are currently used by higher education students.

In this paper, we focused on Faculty of Science, Engineering, and Built Environment (SEBE) students at Deakin University Australia. This research is part of an 8 month supervised honours research project that has been conducted to fulfil the requirements of the Bachelor of Information Technology (Honours) degree. Our primary research question was "what are the positives and negatives specifications of the most popular eReader used by SEBE students at Deakin University based on devices specifications?" However, in answering the primary research questions, we have to identify the following sub-questions: Are SEBE students at Deakin University using eReaders to read eBooks?, What are the three most popular eReaders used by SEBE students at Deakin University Australia?, What are the factors that can motivate SEBE students at Deakin University Australia to read eBooks using an eReader?, What are the factors that can unmotivated SEBE students at Deakin University Australia not to read eBooks using an eReader?, What types of books are usually read by SEBE students at Deakin University Australia?. The metrics as the output of this study provided the comparison of specifications for the three eReader most used by SEBE students at Deakin University.

The scope of this research is limited to the evaluation of eReaders used by higher education students in general and specifically in SEBE at Deakin University. The different brands of eReaders presented within this paper are based on those used by students, as indicated within the survey conducted in SEBE at Deakin University.

This paper consists of six sections: introduction, literature review, methodology and design, survey results, development of metric, and conclusion and future work. The introduction section provides a glance explanation about the paper including the background of conducting the research, the research questions that appeared during the study, the aim of the research, and the research's limitation. The literature review section provides the theory that related to the study, such as the details about eBooks and eReader devices currently existing in the market, and previous studies that relate to this study. The methodology and design section provides the explanation about the method and design used in the research, while the survey result section provides the results of the survey that have been conducted during the research project including demographic, mobile device ownership, and eReader usage. The development of metric section provides the metric that has been created as the outcome of the research followed by the explanation. Finally the conclusion and future work section provides the summary of research findings and presents some ideas about the future research after completing this project.

\section{Literature Review}

An eBook, as a portable file designed to display the digital version of 'written material' from books, magazines, newspapers, and another written sources with less-power and high-resolution device, is able to display digital form of a printed book and can be read using personal computer, smartphone, or dedicated hardware (Educause, 2010). Since the development of the eBook that started in the $19^{\text {th }}$ century by Michael Stern Hart in Project Gutenberg, the reading habits have shifted from the print version of book into the digital version of book at a small cost (Lebert 2009). Nowadays, the presence of eBooks with supported features, such as interactive functions (quizzes and video), search functions, annotation/highlighting capability, and wireless internet capability offer more opportunities than traditional books in hard copies (Rickman, Holzen, Klute, \& Tobin, 2009).

An eReader, as a dedicated electronic device that allows users to read eBook digitally, becomes prosperous with low-power consumption and high-resolution screen (Educause 2010). In the cur- 
rent technology world, eReaders are also used as a learning technology in the education field, with the purpose to provide access to open books digitally (Multimedia \& Internet at School, 2010). There are varieties of eReaders in the market; some of them are designed to be read by computers, for example Apple iPod/iPhone/iPad. However there are some eReaders that are able to dominate the market, such as Kindle by Amazon, Sony eReader by Sony, or Nook by Barnes and Noble (Ma, 2010).

Wilson (2003) distinguishes eBook hardware into three categories, namely, dedicated eBook readers, PDAs and Pocket PCs, and hybrid devices. On the other hand, Sheehan (2013) defines numerous varieties of eReaders, such as computer, smartphone, kindle, nook, iPad/Tablets, Sony, and Kobo.

An Australian education system is categorised into two levels, namely, school education and postsecondary education. Postsecondary education is also known as tertiary education and includes higher education and vocational education and training (VET) that specifically may be defined as education that is provided in university and non-university institutions that award Australian Education Framework (AQF) level 5 to 10 qualifications (Australian Education International, 2011).

According to the Statistics Portal (2014a, 2014b), 37\% of the total number of eReader users belonged to the age group of 18 to 29 and $45 \%$ of the total eReader users were college graduates. Based on the statistics from the last three years, eReader usage in Australia is steadily increasing every year. Since 2010, there were only 7\% of Australians who used eReaders, whereas in 2011 the number increased to $13 \%$, and in 2012 there was a further increase up to $26 \%$ of the eReader users (Nielsen, 2012). There are some factors that influenced higher education students to use eReader for reading eBooks. The eReader manufacturers determine their technical specifications mostly based on market research; hence these specifications do not often directly address students' educational requirements and needs to improve their study performance (Timoko, 2012). However, some students complained that the screen is the obvious issue for many students who prefer to read the EBooks for a long duration of time, due to limitations of chairs, desk and dedicated device (Al-Mahmood, 2014).

\section{Methodology and Design}

A survey, as a systematic method with the objective to construct quantitative data from a group of participants, was used in this research to gather data and information related to demography, reading behaviors, mobile device ownership, accessing eBooks, eReaders usage, frequency, and purpose, future use and motivation, and eReaders and their usability. The survey also generated quantitative and qualitative data from research participants. The objectives of conducting survey were to construct quantitative data from a group of people, gather data by asking people, collect data by interviewing, record answers, and determine "incidence, distribution, and interrelationship" of particular variables in the group of participants (Groves et al., 2013).

The survey participants were students from SEBE at Deakin University. The selection of the participants was based on the Human Ethics Advisory Group (HEAG) rules and regulation in conducting survey in Deakin University. All participants were 18 years old and above.

The survey technique conducted in this research generated quantitative and qualitative data from research participants. The survey discovered information about the most popular eReader used by SEBE Environment students in Deakin University to read eBooks. In addition, this research found out the reason of using specific eReader to read an eBook, types of books being read using eReader and frequency of using an eReader to read eBooks. The survey consisted of five sections. The first and second sections were about participant details and accessing eReader. The eReaders usage, frequency, and purpose data and information were gathered in section three. The last two 
sections were about future use and motivation, and mobile devices, eReader devices and their usability. The first to fourth section generated the quantitative data, and the last section of the survey generated the qualitative data. The example of quantitative data retrieved was the participant's details, such as age, gender, study information and type of students. On the other hand, the qualitative data retrieval was located in the fifth section, for example several things that the participant did not like about his/her eReader.

Survey conducted in the study retrieved data from participants that was completely anonymous. The researcher could not track back the participant's personal details. Specific data collection for this research was retrieved using an online survey. Data from survey were collected via Google Forms and directly stored to Form Response file on the researcher's personal Google Drive account. Data retrieved from Form Response file were analyzed and displayed into different types of form, such as chart, graphics, and tables.

The survey was delivered online to potential participants via an email link. The Administrative Coordinator in SEBE contacted and sent the invitation emails to current students who were enrolled in SEBE. The survey invitation was enclosed with Project's explanation and the Plain Language Statement that consisted of a glance of the project.

\section{Survey Results}

The survey has gathered the information about the most popular eReaders as used by higher education students. The survey was also used to gage whether genuine students were using eReaders in higher education students and if so which devices that they were using. The survey was also used to gather further information about why students selected one device over another and the factors that lead to their continued used of their eReader devices. The survey results of this study are classified into 3 sections: demographic, mobile device ownership, and eReader usage.

\section{Demographic}

This section includes three demographic questions related to the type of student, age, and year of study. Among the 78 survey respondents, 67 participants identified themselves as domestic students and 11 as international students. Most of the survey respondents were Bachelor degree students, where out of 78 students are 60 bachelor degrees students, followed by 17 students and 1 student who enrolled in Honours degree and Master degree. The detailed break-down of the interviewed students are listed in Table 1.

Table 1. The information about the 78 surveyed students. Type of student and age group (row), and accessing educational content (column)

\begin{tabular}{|l|c|c|}
\hline Student type sorted by age groups & \multicolumn{2}{|c|}{ eReader usage to read eBook } \\
\hline Local & Yes & No \\
\hline $18-21$ & 10 & 8 \\
\hline $22-25$ & 9 & 11 \\
\hline $26-30$ & 5 & 4 \\
\hline Above 30 & 13 & 7 \\
\hline International & Yes & No \\
\hline $18-21$ & 1 & 0 \\
\hline $22-25$ & 5 & 1 \\
\hline $26-30$ & 0 & 3 \\
\hline Above 30 & 1 & 0 \\
\hline
\end{tabular}

\section{Mobile Devices Ownership}

In this section, participants were asked to give information about which mobile devices they currently own. Participants were allowed to select multiple devices from the list. Mobile devices provided are smartphone (e.g., mobile phone), tablet (e.g., iPad, Samsung Galaxy Tab, Blackber- 
ry, etc.), eReader (e.g., kindle, nook, sony, kobo, etc.), and other devices. As shown in Figure 1, 93 percent of students owned a smartphone and 7 percent of them owned the other devices.

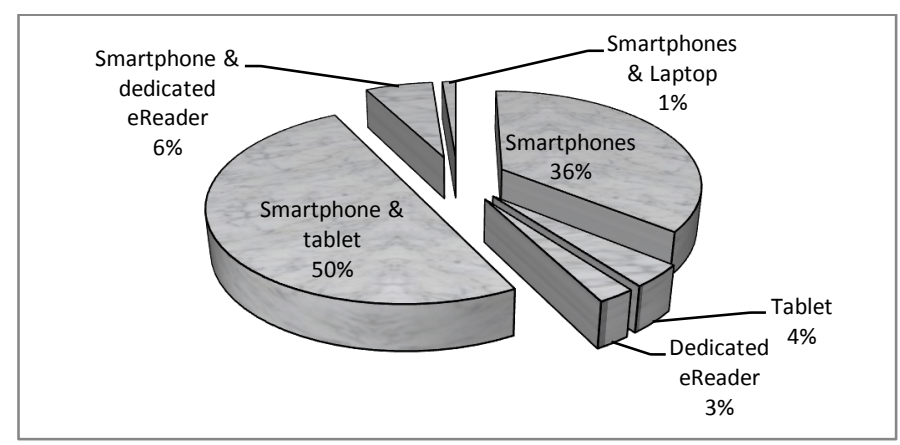

Figure 1. Mobile device ownership

Another question was asked about the specific devices used by students. According to our findings shown in Figure 2, the 'Apple - iPad' was the most popular eReader model used by students which was selected by 49 percent, followed by 'Amazon - Kindle' with 14 percent, 'Samsung Tablet' with 14 percent, and other devices such as Sony Tablet, Asus, Google Play Book, and Adobe Digital with 23 percent.

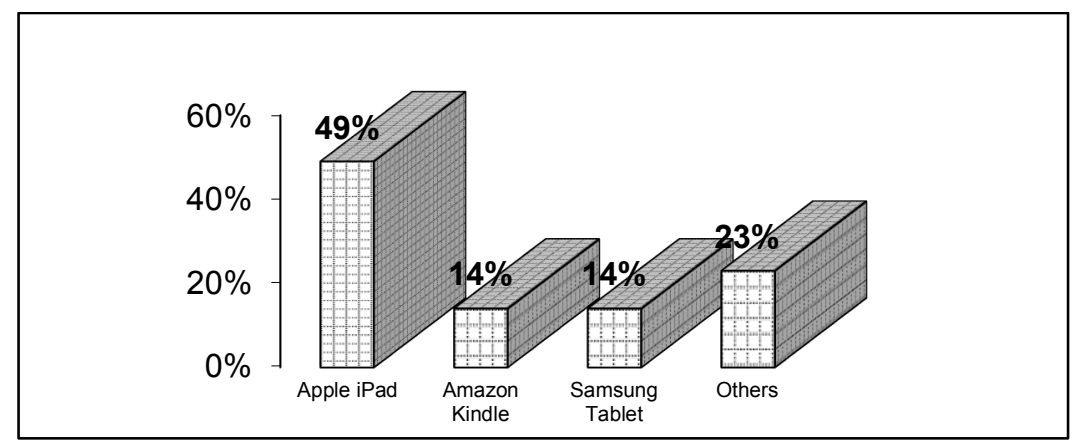

Figure 2. eReader devices owned by the surveyed students

\section{eReader Usage}

Based on the survey results, the factors that most highly encourage students to use eReader to read were convenience (such as able to use anywhere), followed by flexibility (such as able to use anywhere) and portability (such as easy to carry) as shown in Figure 3.

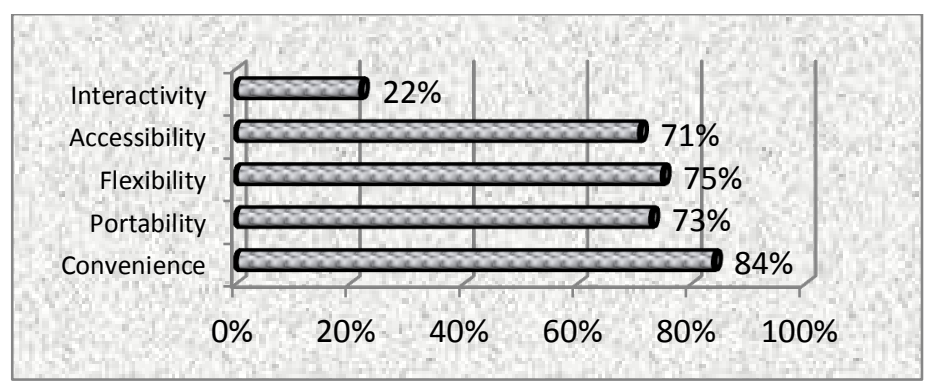

Figure 3. Factors of using eReader 


\section{Development of Metric}

The survey results as presented in the previous section have led to the development of the metrics. Hence this metrics can be used by higher education students as a guide for selection of an appropriate reading device which will match their specific needs. The development of the metrics was the major contribution of this paper because higher education students may use these metrics to rationalize their purchase of eReaders based on the features important to their needs alongside with vendors' technical specifications.

In this section, the specifications of the three eReader selected, iPad Air 2 (Wi-Fi + Cellular), Kindle Fire HDX 8.9 (4G), and Galaxy Note 10.1" (3G, LTE), are elaborated. The three eReader devices from different brands have been selected based on the survey result (see Figure 2). The survey results showed that $49 \%$ of respondents used Apple iPad, $14 \%$ of respondents used Amazon Kindle, and 14\% of respondents used Samsung Tablet. The selection of these specific eReaders was due to the similarity of specifications and features of the devices. Described in Table 2, the specification includes hardware specification, design, display, formats, memory, battery, connectivity, camera, and sensor.

Table 2. Devices specifications and features

Source: Amazon.com Inc. (2014), Apple Inc. (2014), and Samsung (2014)

\begin{tabular}{|c|c|c|c|c|}
\hline \multicolumn{2}{|c|}{ Specification } & iPad & Kindle & Galaxy Note \\
\hline \multicolumn{2}{|c|}{ Operating systems } & equal & equal & equal \\
\hline \multirow[t]{3}{*}{ Design } & Dimension & $* *$ & $*$ & $* * *$ \\
\hline & Weight & $* *$ & $* * *$ & $*$ \\
\hline & Color & $* * *$ & $* *$ & $*$ \\
\hline \multirow[t]{2}{*}{ Display } & Screen size & $* *$ & $*$ & $* * *$ \\
\hline & Resolution & $* *$ & $* * *$ & $* *$ \\
\hline \multirow[t]{4}{*}{ Format } & File & $* *$ & $* * *$ & $* *$ \\
\hline & Image & $* * *$ & $*$ & $* *$ \\
\hline & Video & $* * *$ & $*$ & $* *$ \\
\hline & Audio & $* *$ & $* *$ & $* * *$ \\
\hline \multirow[t]{2}{*}{ Memory } & Internal & $* * *$ & $* *$ & $* *$ \\
\hline & External & none & none & $* * *$ \\
\hline \multirow[t]{2}{*}{ Battery } & Capacity & $* *$ & $*$ & $* * *$ \\
\hline & Life & $* * *$ & $* * *$ & $* * *$ \\
\hline \multicolumn{2}{|c|}{ Connectivity } & equal & equal & equal \\
\hline \multirow[t]{3}{*}{ Camera } & Rear & $* *$ & $* *$ & $* * *$ \\
\hline & Forward & $* * *$ & $* * *$ & $* * *$ \\
\hline & Video & $* * *$ & $* * *$ & $* * *$ \\
\hline \multicolumn{2}{|l|}{ Sensor } & $* * *$ & $* *$ & $* * *$ \\
\hline \multicolumn{2}{|l|}{ Price } & $\$ \$$ & $\$$ & $\$ \$ \$$ \\
\hline
\end{tabular}

The three stars $(* * *)$ means the $1^{\text {st }}$ rank, the two stars $\left({ }^{* *}\right)$ means the $2^{\text {nd }}$ rank, and the one $\operatorname{star}(*)$ means the $3^{\text {rd }}$ rank. The three dollar signs $(\$ \$$ ) means the most expensive, the two dollar signs (\$) means more expensive/normal, and the one dollar sign (\$) means less expensive.

Deciding upon a specific eReader as a device to access eBooks might take time for customers without the adequate background that influences them to purchase the specific device.

This research has created a set of metrics for the usefulness of the eReader most used by SEBE students at Deakin University. The metrics can be used for future customers as a consideration when they are facing the problem about which eReader they need to purchase based on the specifications provided on the device. 
The Apple iPad Air 2 is highly recommended for students who are considering the supported format (including file format, image format, audio format, and video format) and design specification (including dimension, weight, and colour). This device has supported file format including .doc and .docx (Microsoft Word), .htm and .html (Web Pages), .pages (Pages), .pdf (Preview and Adobe Acrobat), .txt (Text), and .rft (Rich Text Format), followed by image format including .jpeg, .png, .gif, .bmp, .wbmp, .webp, .tiff, and .jiff, audio format including QuickTime Movie (.mov), MPEG-4 (.mp4, .m4v), MPEG-2 (OS X Lion or later), MPEG-1, 3GPP, 3GPP2, AVCHD (OS X Mountain Lion or Later), AVI (Motion JPEG only), and DV, and video format including .wav, .mp3 and .mp4, aac lc/ltp, he-accv1 and he-accv1, .aiff, .audible, and apple lossless. In addition, this device is excellent in design specification where the dimensions of the device, weight, and color have the best rating among the other two devices (Amazon Kindle HDX 8.9 and Samsung Galaxy Note 10.1").

The Amazon Kindle Fire HDX is highly recommended for students who are concerned about the device prices because this device offers the cheapest price among the other devices. Students need to spend about $\$ 379$ for purchasing this device, however Apple iPad offers a quite high price for purchasing the device at about $\$ 499$, followed by Samsung Galaxy Note 10.1" that has the most expensive price by $\$ 799$ to purchase this device.

The Samsung Galaxy Note 10.1" tablet is highly recommended for students who are considering the camera specification, the battery life, the supported memory, and the device display. This device has the high resolution camera with forward facing camera at $8.0 \mathrm{MP}$ and rear facing camera at 2.0MP, whereas the other two devices (Apple iPad and Kindle Fire HDX) only provide 1.2MP for rear facing camera resolution.

In general, the three eReader devices that have been compared have the same specification in connectivity specification and operating systems. The connectivity of these devices are Wi-Fi $802.11 \mathrm{a} / \mathrm{b} / \mathrm{g} / \mathrm{h} / \mathrm{ac}$. On the other hand, these devices have different mobile operating systems run in the devices, such as iPad Air 2 operates in iOS Operating System, Kindle Fire HDX operates in Fire OS 3.0 Mojito Operating System, and Samsung Galaxy Note 10.1" operates in Android 4.3 (JB), however these differences cannot be measured because the preference of using the specific operating system for every person is different.

\section{Conclusion and Future Work}

\section{Conclusion}

The study objective was to evaluate the usefulness of eReader devices used by higher education students in Australia, specifically in SEBE at Deakin University. It was observed that convenience, flexibility, and portability are the factors that most influenced respondents to use eReader devices in accessing eBooks.

From the survey results, it was determined that the three most popular eReader devices used by SEBE students at Deakin University were Apple iPad, Amazon Kindle, and Samsung Tablet. The Apple iPad device was the most popular eReader device used by students with a $49 \%$ usage rate, followed by Amazon Kindle device with 14\%, and Samsung Tablet with 14\%.

The results from the survey conducted during the research also showed information about the factors that influenced respondents to use eReaders in accessing eBooks. Based on the survey result analysis, the components in the usefulness metric are defined. The survey result showed that convenience, accessibility, portability, flexibility, and interactivity were the factors that influenced respondents to use eReaders. The convenience, flexibility, and portability factors include the design, display, and battery life of the device, such as dimension, weight, colour, screen size, and 
resolution. Accessibility factors include supported file, image, video, and audio format, and supported internal and external memory. The interactivity factors include operating systems used on the device and additional features to support the usability of devices, such as connectivity, camera, and sensor.

\section{Future Work}

The future work for this research will be to study users' experiences in using eReader devices evaluated in this research. Based on this research, the eReaders most used by higher education students in Australia were Apple iPad, Amazon Kindle, and Samsung Tablet. Future research will be conducted to validate the authenticity of the eReader devices usefulness metrics created from the current research.

The research participants for the future work will be given the three eReader devices during a certain amount of time to read an eBook. Their experiences while reading the same eBook in the different devices will be recorded and analyzed. The description about the participants' experience using the three most eReaders provided during the study will be documented and elaborated, supported by the recent studies from other researchers who have closely related studies with this future work.

The future work data gathering and analysis will use the qualitative research approaches because the study will evaluate the authenticity of the usefulness of the most three popular eReader used by higher education students and make the documentation in the form of the study.

\section{References}

Al-Mahmood, R. (2014). Re-imagining the university: Vibrant matters and radical research paradigms for the 21st century. In H.Carter, M. Gosper,\& J.Hedberg (Eds.), Electronic dreams. Proceedings ASCILITE 2013 Sydney (pp.23-36).

Amazon.com Inc. (2014). Kindle. Retrieved August 8, 2014, from https://www.amazon.comgp/product/B0015SB16/ref=topnav_storetab_kstore

Apple Inc. (2014). iPad Support. Retrieved August 8, 2014, from https://www.apple.com/supportt/ipad/

Australian Education International. (2011). Country education profiles Australia. Retrieved August 21, 2014, from https://aei.gov.au/Services-And-Resources/Services/Country-Education-Profiles/AboutCEP/Documents/Australia.pdf

Colorado, J. (2012, June). Teaching 21st Century Learners with Mobile Devices. In World Conference on Educational Multimedia, Hypermedia and Telecommunications (pp. 2247-2252).

Educause. (2010). 7 things you should know about ereaders. Retrieved March 26, 2014, from https://net.educause.edu/ir/library/pdf/ELI7058.pdf

Groves, R.M., Fowler, F.J., Couper, M.P., Lepkowski, J.M., Singer, E.\& Tourangeau, R. (2013). Survey methodology. New Jersey:Wiley.

Lebert, M. (2009). A short history of eBooks. University of Toronto: NEF.

Ma, X. (2010). Market analysis on EReaders into the market of university students. 3rd International Conference on Information Management, Innovation Management and Industrial Engineering.

Multimedia \& Internet at School. (2010). EReaders, Etextbooks, EContent, Elearning, E-Everything. MultiMediaInternet School. 9-14.

Nielsen. (2012). The Australian online consumer landscape. Retrieved August 8, 2014, from http://workspace.unpan.org/sites/internet/documents/S6AU12\%20The\%20Australian\%20Online \%20C onsumer\%20Landscape.pdf 
Nielsen. (2014). The Australian online landscape review. Retrieved August 8, 2014, from https://www.iabaustralia.com.au/uploads/uploads/201404/1398816000_4eab168d68742820c049bd45c1dd6e82.pdf

Rickman, J.T., Holzen, R.V., Klute, P.\& Tobin, T. (2009). A campus-wide e-textbook initiative. Retrieved August 8, 2014, from http://www.educause.edu/ero/article/campus-wide-e-textbook-initiative

Samsung. (2014). Galaxy Tabs. RetrievedAugust 8, 2014, from https://www.samsung.com/us/mobile/galaxy-tab/

Sena, J.A. (2011). The ebooks and ereaders: A portrait of technology acceptance. International Journal of Global Management Studies, 3(1), 47-61.

Sheehan, K. (2013). The eBook revolution (A premier for librarians on the front lines.) CA: Library Unlimited.

Stephens, W. (2012). Deploying ereaders without buying ebooks. Knowledge Quest. 40(3), 40-43.

The Statistics Portal. (2014a). EReader readers in the United States in 2014 by age. Retrieved August 8, 2014, from http://www.statista.com/statistics/249767/eReader-readers-in-the-us-by-age/

The Statistic Portal. (2014b). EReader readers in the United States in 2014 by education level. Retrieved August 8, 2014, from http://www.statista.com/statistics/249774/eReader-readers-in-the-us-byeducation-level/

Timoko, T. (2012). Mobile learning, exploring the possibilities for rangatahi. In M.Brown, M.Harnett,\& T.Stewart (Eds.). (2012).Future challenges, sustainable futures. Proceedings of ASCILITE Wellington 2012. (pp.920-924).

Wilson, R (2003). Ebook readers in higher education. Educational Technology \& Society. 6(4), 8-17.

\section{Biographes}

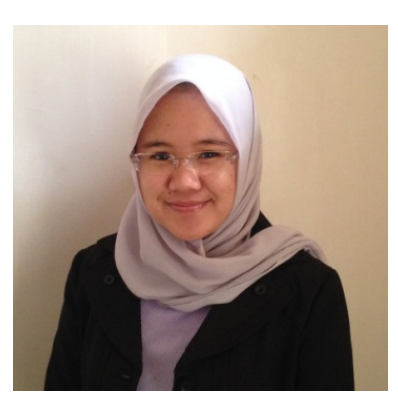

Dwi Puspita Sari has completed her Bachelor of Information Technology (Honours) at Deakin University Australia with First Class of Honours in December 2014. Her honours thesis is about evaluating the usefulness of eReaders for higher education students. Previously, she has completed Bachelor of Information Systems at UIN Syarif Hidayatullah Jakarta, Indonesia in July 2014 and Bachelor of Information Technology with Distinction majoring in Computer Science and Software Development in July 2013. After completing her honours degree at Deakin University, she received summer vacation scholarship to work on "A Service Remote Agent Framework for Connecting to Scientific Computing Services" project at Commonwealth Scientific and Industrial Research Organisation (CSIRO) located in Clayton, Victoria, Australia. Once completing the project in late February 2015, she started working as a teaching staff at Sekolah Tinggi Manajemen dan Ilmu Komputer Musi Rawas (STMIK MURA) located in Lubuklinggau, South Sumatera, Indonesia.

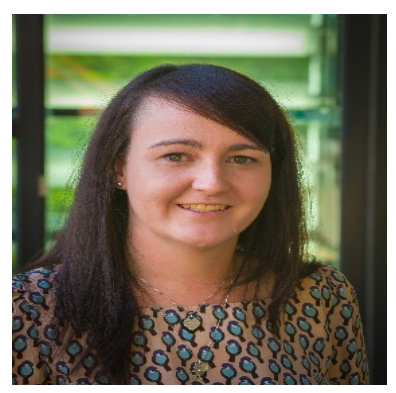

Dr. Elicia Lanham is a Lecturer of Information Technology at Deakin University in Australia, where she is the discipline leader for the Interactive Media stream. She is a member of the Information Technology for Future Education research group within the School of Information Technology at Deakin, which aligns with her research interests of: Blended Learning, Mobile Teaching and Education, and IT for Future Education. DR Lanham is also a current member of the Australian Computer Society (ACS). 


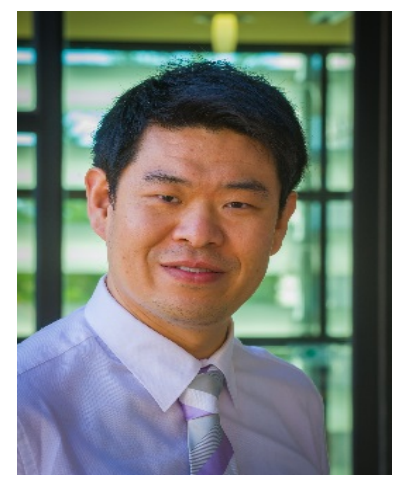

Dr. Lei Pan is a Lecturer of Information Technology at Deakin University in Australia where he leads the Information Technology Security stream. His research interests include Information Technology Security, Higher Education, and assessment. He is a current member of the ACS, IEEE, and contributes to several other academic panels. 